\title{
Research Article \\ Effect of Sr-P Interaction on the Microstructure and Tensile Properties of A413.0 Type Alloys
}

\author{
A. M. Samuel, ${ }^{1}$ H. W. Doty, ${ }^{2}$ S. Valtierra, ${ }^{3}$ and F. H. Samuel ${ }^{1}$ \\ ${ }^{1}$ Université du Québec à Chicoutimi, Chicoutimi, QC, Canada \\ ${ }^{2}$ Materials Engineering, General Motors, 823 Joslyn Avenue, Pontiac, MI 48340, USA \\ ${ }^{3}$ Corporativo Nemak, S.A. de C.V., P.O. Box 100, 66221 Garza Garcia, NL, Mexico
}

Correspondence should be addressed to F. H. Samuel; fhsamuel@uqac.ca

Received 21 September 2016; Accepted 13 November 2016

Academic Editor: Peter Majewski

Copyright (C) 2016 A. M. Samuel et al. This is an open access article distributed under the Creative Commons Attribution License, which permits unrestricted use, distribution, and reproduction in any medium, provided the original work is properly cited.

\begin{abstract}
The present study was performed on low magnesium A413.0 type alloys. The results show that strontium (Sr) is mainly concentrated in the silicon particles. Overmodification occurs when $\mathrm{Sr}$ precipitates in the form of $\mathrm{Al}_{2} \mathrm{SrSi}_{2}$, which takes place over a wide range of temperatures. The first peak occurs following the precipitation of $\alpha$-Al, the second peak is merged with the precipitation of eutectic silicon $(\mathrm{Si})$, and the third peak is a posteutectic reaction. Introduction of phosphorus $(\mathrm{P})$ to Sr-modified alloys leads to the formation of $(\mathrm{Al}, \mathrm{P}, \mathrm{Sr})_{2} \mathrm{O}_{5}$ compound, which reduces the modification effectiveness of Sr. Therefore, in the presence of $\mathrm{P}$, the amount of added Sr should exceed $200 \mathrm{ppm}$. For the same levels of P, the tensile parameters of well modified alloys (233 ppm Sr) are relatively higher than those partially modified with $\mathrm{Sr}$ (about $60 \mathrm{ppm} \mathrm{Sr}$ ) containing the same amount of P. During solution heat treatment, coarsening of the eutectic Si particles occurs by the growth of some particles at the expense of the dissolution of the smaller ones, as well as by the collision of nearby particles.
\end{abstract}

\section{Introduction}

The mechanical properties of Al-Si alloys strongly depend on many factors including chemical composition, molten metal processing and casting techniques, heat treatment, and microstructure, in particular the morphology of the eutectic silicon. In the normal as cast condition, the eutectic $\mathrm{Si}$ particles occur as brittle acicular flakes in the microstructure. Such acicular particles act as crack initiators and provide easy paths for fracture and, hence, reduce the mechanical properties of the alloy [1].

Groups IA and IIA elements are well known to act as effective modifiers in $\mathrm{Al}-\mathrm{Si}$ alloys where, with the addition of elements like $\mathrm{Ca}, \mathrm{Na}, \mathrm{Sr}$, and $\mathrm{Sb}$, the morphology of the eutectic Si particles can be altered to a fine lamellar or fibrous eutectic network. The degree of Si particle modification achieved by the addition of $\mathrm{Sr}$ is similar to that obtained by $\mathrm{Na}$ and $\mathrm{Ca}$. The most acceptable explanation of the change in the eutectic Si morphology suggests that the growth of silicon particles within the eutectic regions is prevented by the addition of such modifiers [2-5].
According to Haque and Maleque [1] who studied the Sr modification of Al-Si piston alloys, the extent to which $\mathrm{Sr}$ is able to refine the eutectic structure strongly depends on its concentration in the molten alloy before the start of solidification, as well as on the cooling rate. The refined structure and the properties reach a maximum at $\mathrm{Sr}$ concentration of about $0.1 \%$ and then tend to decrease with further Sr addition beyond this level. Owing to the fact that the microstructure of Sr-modified alloys contains a large amount of rounded silicon particles with no primary silicon crystals, the addition of $\mathrm{Sr}$ leads to an increase in the tensile strength and the hardness of the alloys.

In reviewing the mechanisms of eutectic modification in Al-Si alloys, several researchers [6-8] have reported that many of the hypotheses proposed in the literature assume that (a) the eutectic Si phase nucleates on the primary $\alpha$-Al dendrites and (b) the modifier inhibits the growth of the Si phase, causing the transformation of the Si particle morphology from plate-like to fibrous. However, they are unable to explain the phenomena associated with modification, such as the large undercooling observed with the addition of modifier, 
TABLE 1: Chemical composition of as-received A413.0 alloy.

\begin{tabular}{lccccccccc}
\hline \multirow{2}{*}{ Alloy } & & \multicolumn{9}{c}{ Elements (wt.\%) } & & & \\
& $\mathrm{Cu}$ & $\mathrm{Mg}$ & $\mathrm{Mn}$ & $\mathrm{Si}$ & $\mathrm{Fe}$ & $\mathrm{Zn}$ & $\mathrm{Ti}$ & Others (total) & Bal. \\
\hline A413.0 & 1.0 & 0.1 & 0.35 & $11-13$ & 2.0 & 0.5 & - & $\mathrm{Al}$ \\
\hline
\end{tabular}

TABLE 2: Chemical compositions of A413 alloys containing Sr and P.

\begin{tabular}{lccccccccccccccc}
\hline Element (wt.\%) & A413.0 & A413S & $413 \mathrm{P}$ & $\mathrm{I}$ & $\mathrm{II}$ & $\mathrm{III}$ & $\mathrm{IV}$ & $\mathrm{V}$ & $\mathrm{VI}$ & $\mathrm{VII}$ & $\mathrm{VIII}$ & $\mathrm{IX}$ \\
\hline $\mathrm{Sr}$ & $<0.0002$ & $\mathbf{0 . 0 3 4 0}$ & $<0.0020$ & $\mathbf{0 . 0 1 2 8}$ & $\mathbf{0 . 0 1 0 3}$ & $\mathbf{0 . 0 0 5 6}$ & $\mathbf{0 . 0 2 3 3}$ & $\mathbf{0 . 0 2 7 0}$ & $\mathbf{0 . 0 2 8 4}$ & $\mathbf{0 . 0 1 7 2}$ & $\mathbf{0 . 0 1 9 5}$ & $\mathbf{0 . 0 2 4 9}$ \\
$\mathrm{Mg}$ & 0.04 & 0.038 & 0.032 & 0.028 & 0.029 & 0.028 & 0.037 & 0.037 & 0.036 & 0.037 & 0.037 & 0.036 \\
$\mathrm{Cu}$ & 0.366 & 0.382 & 0.34 & 0.31 & 0.32 & 0.34 & 0.31 & 0.37 & 0.25 & 0.31 & 0.36 & 0.38 \\
$\mathrm{Ni}$ & 0.0016 & 0.0016 & 0.08 & 0.08 & 008 & 0.08 & 0.08 & 0.08 & 0.08 & 0.08 & 0.08 & 0.08 \\
$\mathrm{~B}$ & 0.0034 & 0.0034 & 0.0011 & 0.0032 & 0.0015 & 0.0028 & 0.0019 & 0.0017 & 0.0028 & 0.0024 & 0.0030 & 0.0028 \\
$\mathrm{Zn}$ & 0.1128 & 0.1128 & 0.096 & 0.099 & 0.101 & 0.101 & 0.099 & 0.101 & 0.099 & 0.100 & 0.100 & 0.098 \\
$\mathrm{P}$ & 0.0001 & 0.0001 & $\mathbf{0 . 0 0 0 8}$ & $\mathbf{0 . 0 0 3 6}$ & $\mathbf{0 . 0 0 5 3}$ & $\mathbf{0 . 0 0 5 6}$ & $\mathbf{0 . 0 0 4 7}$ & $\mathbf{0 . 0 0 6 1}$ & $\mathbf{0 . 0 0 3 4}$ & $\mathbf{0 . 0 0 3 6}$ & $\mathbf{0 . 0 0 4 0}$ & $\mathbf{0 . 0 0 5 0}$ \\
$\mathrm{Si}$ & 12.81 & 12.11 & 12.75 & 12.66 & 12.76 & 12.67 & 12.40 & 12.46 & 12.81 & 12.89 & 12.89 & 12.84 \\
$\mathrm{Fe}$ & 0.0629 & 0.064 & 0.69 & 0.67 & 0.69 & 0.69 & 0.67 & 0.66 & 0.67 & 0.69 & 0.69 & 0.68 \\
$\mathrm{Ti}$ & 0.065 & 0.065 & 0.060 & 0.061 & 0.065 & 0.065 & 0.061 & 0.062 & 0.059 & 0.059 & 0.063 & 0.067 \\
$\mathrm{Mn}$ & 0.716 & 0.720 & 0.287 & 0.285 & 0.286 & 0.286 & 0.275 & 0.272 & 0.277 & 0.277 & 0.280 & 0.273 \\
$\mathrm{Cr}$ & 0.2804 & 0.28 & 0.051 & 0.051 & 0.052 & 0.052 & 0.050 & 0.049 & 0.049 & 0.049 & 0.049 & 0.048 \\
$\mathrm{~Pb}$ & 0.0551 & 0.056 & 0.0058 & 0.0058 & 0.0058 & 0.0059 & 0.0060 & 0.0058 & 0.0058 & 0.0061 & 0.0062 & 0.0059 \\
$\mathrm{Al}$ & Bal. & Bal. & Bal. & Bal. & Bal. & Bal. & Bal. & Bal. & Bal. & Bal. & Bal. & Bal. \\
\hline
\end{tabular}

or the occurrence of modification with the use of superheat or a high solidification rate instead of a modifier.

During elevated temperature treatments for extended periods (i.e., thermal modification), changes in the Si particle morphology can occur in several stages. Initially, the Si particles are likely to undergo necking and gradual fragmentation. The fragmentation stage leads to a decrease in the average $\mathrm{Si}$ particle size and an increase in the average particle density. The fragmented particles then spheroidize and coarsen. As a result of the onset of coarsening, an increase in the average size of the particles and a decrease in the average number of particles are observed [4].

Aluminum alloy A413 is considered to be a binary Al-Si alloy suitable for the production of die castings because of its high $\mathrm{Si}$ content of about $11 \mathrm{wt} . \%$ which yields high castability. This alloy is characterized by moderate strength and ductility values in conjunction with good wear and corrosion resistance factors. Alloy A413 is also a general purpose alloy which may be used for producing numerous large castings, including complicated parts with thin sections and fatigueresistant castings. This alloy is a recommended choice for food and dental equipment and also for critical components in marine, ornamental, and architectural applications [7-10].

The present study was undertaken to emphasize the role of Sr-P interaction on the microstructure in terms of size and morphology of both primary and eutectic Si particles and their influence on the alloy tensile properties.

\section{Experimental Procedure}

The A413.0 casting alloy used in this study was supplied in the form of $12.5 \mathrm{~kg}$ ingots. The chemical composition of the base alloy used for this research is listed in Table 1. The alloy ingots were cut into smaller pieces, dried, and melted in a $150 \mathrm{~kg}$ capacity $\mathrm{SiC}$ crucible, using an electrical resistance furnace. The melting temperature was maintained at $750 \pm 5^{\circ} \mathrm{C}$. All of the 413 alloy melts prepared were grain-refined by adding 0.22 wt.\% $\mathrm{Ti}$ in the form of rods of $\mathrm{Al}-5 \mathrm{wt} . \% \mathrm{Ti}-1 \mathrm{wt} . \% \mathrm{~B}$. Strontium and phosphorus were added in the form of Al$10 \% \mathrm{Sr}$ and $\mathrm{Cu}-2 \% \mathrm{P}$ master alloys, respectively. The melts were degassed for $\sim 15-20 \mathrm{~min}$ with a rotary graphite impeller at $\sim 150 \mathrm{rpm}$, using pure dry argon injected into the molten metal at a constant rate of $20.39 \mathrm{~m}^{3} / \mathrm{h}$. The melt was then carefully skimmed to remove oxide layers from the surface.

The melt was poured into an ASTM B-108 permanent mold (preheated at $450^{\circ} \mathrm{C}$ to drive out moisture) for preparing the tensile test bars. Each casting provided two test bars, with a gauge length of $70 \mathrm{~mm}$ and a cross-sectional diameter of $12.7 \mathrm{~mm}$. Three samplings for chemical analysis were also taken at the time of the casting. This was done at the start, the middle, and end of the casting process to ascertain the exact chemical composition of each alloy. The chemical analysis was carried out using a SPECTROLAB-Jr CCD Spark Analyzer, which provided the actual chemical compositions of the alloys produced. Table 2 shows the chemical compositions and alloy codes of the final alloys. Tensile test bars were T6 heat-treated which comprised solution heat treating at $505^{\circ} \mathrm{C} / 8 \mathrm{~h}$, followed by quenching in warm water at $60^{\circ} \mathrm{C}$, and then artificial aging for $5 \mathrm{~h}$ at $155^{\circ} \mathrm{C}, 180^{\circ} \mathrm{C}, 200^{\circ} \mathrm{C}, 220^{\circ} \mathrm{C}$, and $240^{\circ} \mathrm{C}$, followed by air cooling.

In order to obtain the solidification curves and to identify the main reactions and corresponding temperatures occurring during the solidification of 413 alloys, thermal analysis of these melt compositions was carried out. Ingots of the as-received commercial A413.0 alloy were cut into smaller pieces, cleaned, and then dried to prepare the required alloy 


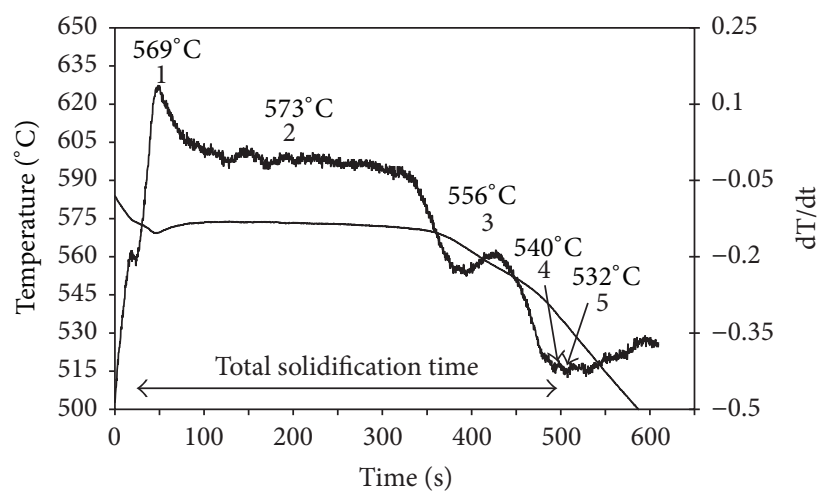

FIGURE 1: Temperature-time solidification curve and its first derivative of the base alloy: (1) precipitation of $\alpha$-Al network, (2) precipitation of $\mathrm{Al}-\mathrm{Si}$, (3) precipitation of Fe intermetallics, (4) precipitation of $\mathrm{Al}_{2} \mathrm{Cu}$, and (5) end of solidification.

compositions. The melting process was carried out in a cylindrical graphite crucible of $2 \mathrm{~kg}$ capacity, using an electrical resistance furnace. The melting temperature was kept at $750^{\circ} \mathrm{C}$, while the alloys were grain-refined by adding $0.2 \% \mathrm{Ti}$ as $\mathrm{Al}-5 \% \mathrm{Ti}-1 \% \mathrm{~B}$ master alloy in rod form. A high sensitivity Type-K (chromel-alumel) thermocouple, which has to be insulated using a double-holed ceramic tube, is attached to the centre of the graphite mold. The temperature-time data is collected every 0.1 second using a high speed data acquisition system. From this data, the solidification curves and the first derivative curves for a number of selected alloys were plotted in order to identify the main reactions occurring during solidification with the corresponding temperatures, as well as the various phases which constitute the microstructure of each alloy.

All tensile samples were tested to failure at room temperature using an MTS servohydraulic mechanical testing machine at a strain rate of $4 \times 10^{-4} \mathrm{~s}^{-1}$ and an extensometer. Five samples from each condition were tested; the ultimate tensile strength (UTS), $0.2 \%$ offset yield strength (YS), and percent elongation ( $\% \mathrm{El}$ ) were obtained from the data acquisition system.

The microstructural characteristics of the alloys were examined using an optical microscope-image analysis system, where quantitative measurements of the eutectic Si particle characteristics were carried out. The intermetallics present were identified using an electron probe microanalyzer (EPMA) coupled with energy dispersive X-ray (EDX) and wavelength dispersive spectroscopic (WDS) facilities; a Jeol JXA-8900L WD/ED combined microanalyzer (operating at $20 \mathrm{kV}$ and $30 \mathrm{nA}$ ) was used in the present study.

\section{Results and Discussion}

\subsection{Microstructural Characterization}

3.1.1. Thermal Analysis (Dendrite Arm Spacing $\sim 68 \mu \mathrm{m}$ ). Figure 1 shows the temperature-time curve obtained from the thermal analysis casting of the base alloy, revealing the main four reactions. The total solidification time is about
450 seconds. Figure 2(a) presents the backscattered electron image of a primary Si particle in alloy V (containing $240 \mathrm{ppm}$ $\mathrm{Sr}$ and $61 \mathrm{ppm} \mathrm{P)}$. As can be seen, the black spots are located almost at the centre of the Si particle. The associated WDS analysis (Table 3) reveals that these spots are a mixture of different oxides, mainly $\mathrm{Al}_{2} \mathrm{O}_{3}$ and $\mathrm{AlPSrO}$, as confirmed by the $\mathrm{X}$-ray images showing the element distribution within the black spots. Moustafa et al. [11] studied the effect of $\mathrm{P}$ addition in $\mathrm{Al}-24 \% \mathrm{Si}$ alloys. Their results show that $\mathrm{P}$ added to the high-Si hypereutectic component provides prerefined primary Si particles. Since most of the P is tied up in AlP particles within the preexisting primary $\mathrm{Si}$, the $\mathrm{Sr}$ added to the low Si liquid component cannot be neutralized and is available for effective modification during eutectic solidification. Tavitas-Medrano et al. [12] also reported on the nucleation of primary Si on AlP compound in 413 type alloys.

Al-Helal et al. [13] proposed a thermodynamic model to predict the formation of AlP in Al-Si alloys. The results reveal that even for extremely low $\mathrm{P}$ content and large undercooling the direct nucleation of Si on primary $\mathrm{Al}$ does not occur but is triggered by the formation of AlP under clean conditions. The $\mathrm{P}$ threshold is not trivial, since it varies from zero to $7.4 \mathrm{ppm} \mathrm{P}$ for hypoeutectic alloys, which is just within or below the commercial purity range of regular Al-Si cast alloys. According to Samuel et al. [14], the nucleation of Si during the solidification of Al-Si hypoeutectic alloys appears to result from a hierarchy of nucleating substrates operating at progressively lower temperatures: (1) AlP, whose generally particulate morphology can initiate the formation of compact Si particles as seen in hypereutectic alloys, (2) oxide bifilms alone, whose planar form creates plate-like Si morphologies, and (3) a currently unknown nucleant that initiates the coral eutectic growth morphology. In another study, Liang and Schmid-Fetzer [15] reported that the unmodified silicon particles are nucleated by AlP, which has in turn nucleated on oxide bifilms.

The effect of Sr-P interaction on the morphology of the eutectic Si particles is presented in Figure 3. Figure 3(a) reveals that when the $\mathrm{P}$ content is as low as $8 \mathrm{ppm}$, it has no effect on the Sr modification efficiency or the precipitation 


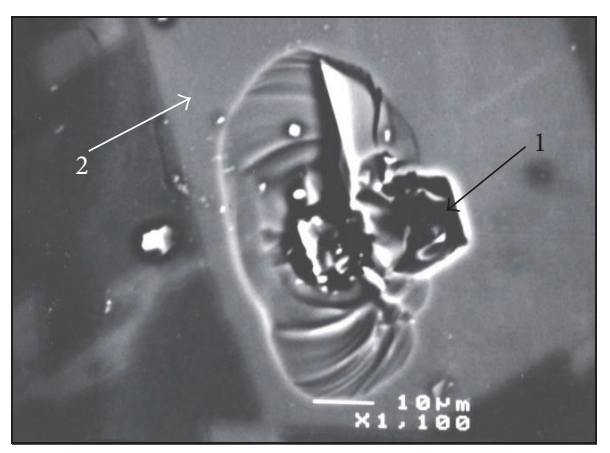

(a)

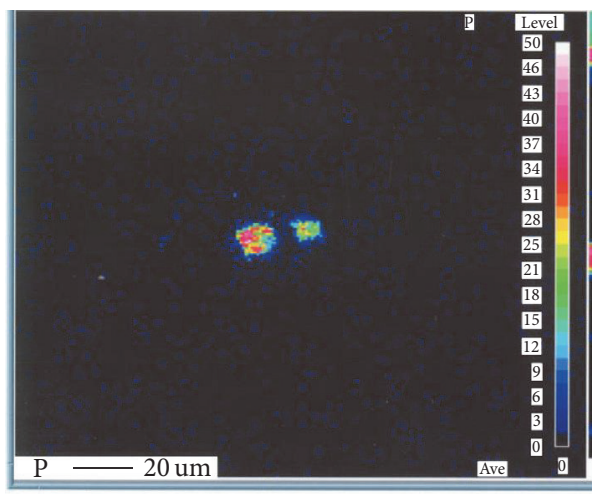

(c)

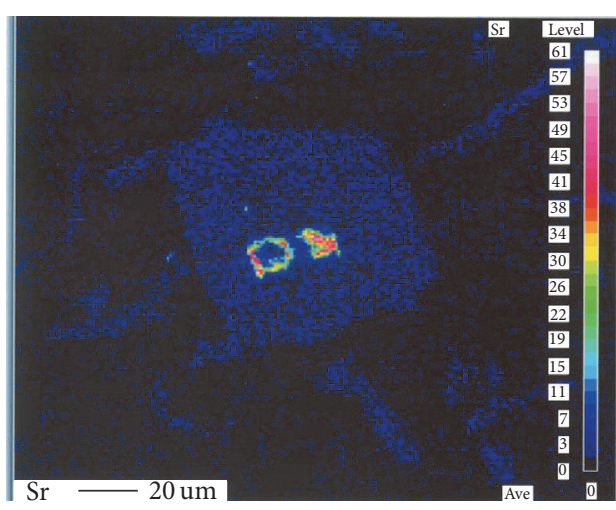

(b)

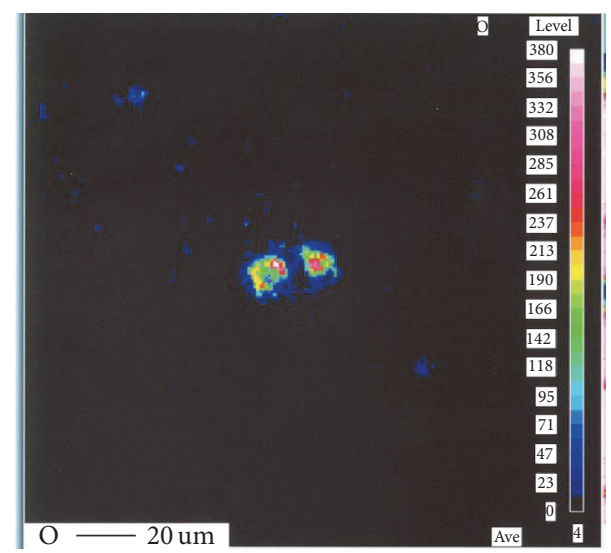

(d)

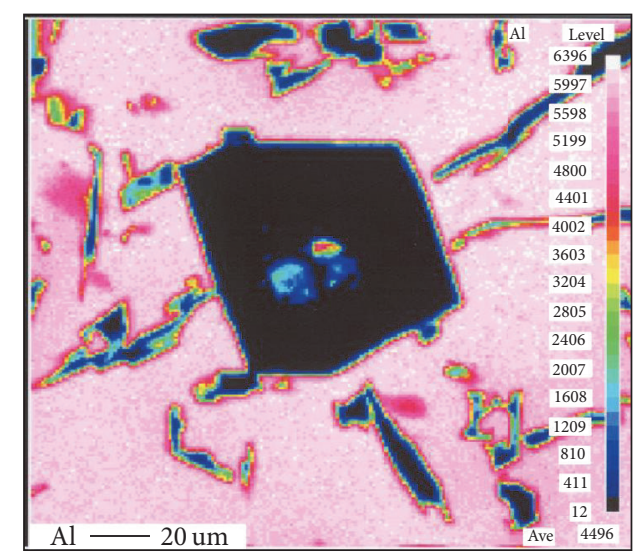

(e)

Figure 2: (a) Backscattered electron image, (b) Sr, (c) P, (d) O, and (e) Al distribution in the black spot.

sequence. Increasing the Sr content resulted in the precipitation of Sr-rich intermetallics in the form of tetrahedral particles as shown in Figure 3(b). The WDS analysis shows that these particles are $\mathrm{Al}_{2} \mathrm{SrSi}_{2}[16,17]$, indicating overmodification. When the concentration of $\mathrm{P}$ increased to $36 \mathrm{ppm}$, clear demodification took place, as observed in Figure 3(c). The broken line in Figure 3(c) reveals the progress of the demodification zone (marked (1)) towards the well modified zone (marked (2)). Further increase in the P content resulted in more or less complete demodification. Figure 4 illustrates the distribution of $\mathrm{Sr}$ in the eutectic Si particles shown in Figure 3(a).

Figure 5 reveals that, in alloy II, containing $103 \mathrm{ppm}$ $\mathrm{Sr}$ and $60 \mathrm{ppm} \mathrm{P}$, areas close to the $\beta-\mathrm{Al}_{5} \mathrm{SiFe}$ platelets are modified (area marked (2)) compared to the Si particles away from the $\beta$-phase (area marked (3)). Thus it may be concluded that $\mathrm{Sr}$ concentration around $\beta$-phase platelets is relatively higher than $\mathrm{Sr}$ in areas away from the $\mathrm{Fe}$ 


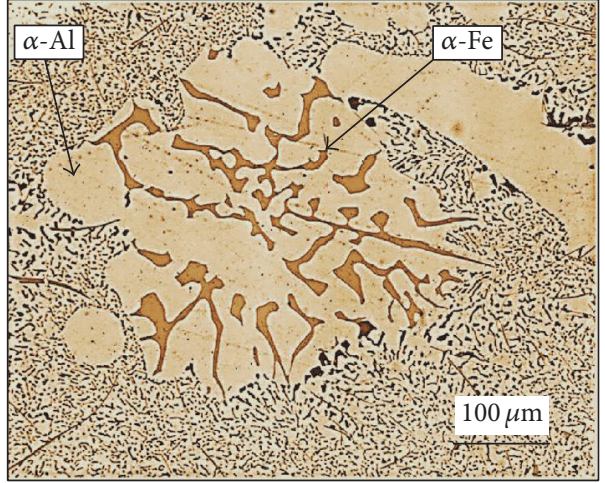

(a)

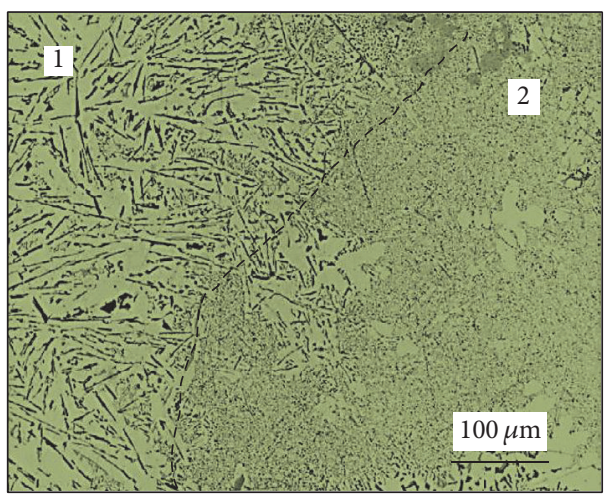

(c)

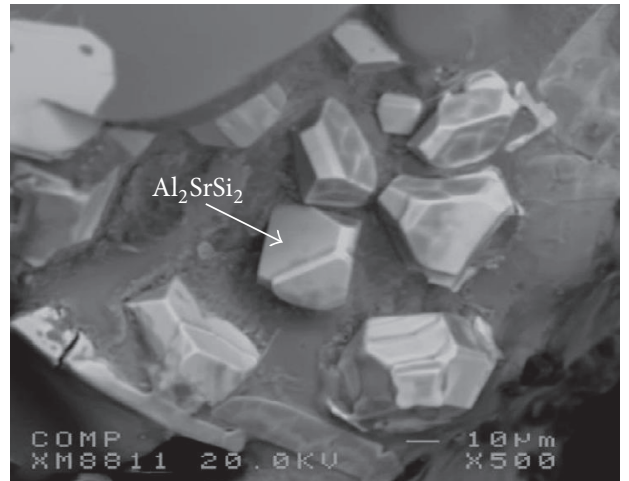

(b)

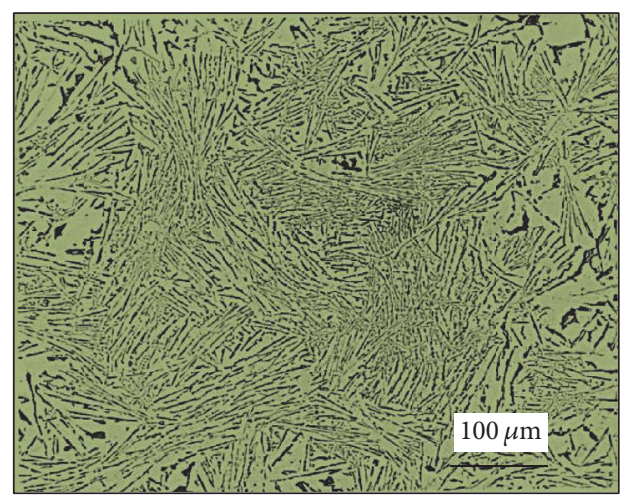

(d)

FIGURE 3: Morphology of the eutectic Si particles in the as cast condition for A413 alloy containing (a) 200 ppm Sr; note the precipitation of $\alpha$-Fe within the $\alpha$-Al dendrite; (b) 340 ppm Sr; (c) 103 ppm Sr +53 ppm P; and (d) 56 ppm Sr + 56 ppm P (see Table 3).

TABle 3: Compositions of the intermetallic observed at the centre of the primary Si particle shown in Figure 2(a).

\begin{tabular}{|c|c|c|c|c|}
\hline Phase \# & Elements & At.\% & Form and color & Suggested composition \\
\hline \multirow{5}{*}{1} & $\mathrm{Al}$ & 47.53 & \multirow{5}{*}{ Spots, black } & \multirow{5}{*}{$\mathrm{Al}_{2} \mathrm{O}_{3}+\mathrm{AlPSrO}$} \\
\hline & $\mathrm{Sr}$ & 4.38 & & \\
\hline & $\mathrm{P}$ & 3.15 & & \\
\hline & $\mathrm{O}$ & 44.94 & & \\
\hline & Total & 100 & & \\
\hline \multirow{3}{*}{2} & $\mathrm{Al}$ & 4.24 & \multirow{3}{*}{ Platelet, gray } & \multirow{3}{*}{$\mathrm{Si}$} \\
\hline & $\mathrm{Si}$ & 95.68 & & \\
\hline & Total & 100.00 & & \\
\hline
\end{tabular}

intermetallics. Figure 5(b) exhibits the concentration of $\mathrm{Sr}$ in areas surrounding the $\beta$-phase. The mechanism explaining this observation is, however, out of the scope of the present work.

Table 4 summarizes the characteristics of the eutectic Si particles in the as cast condition. The main observations that could be made are listed as follows:

(1) The aspect ratios for alloys I and III are the lowest due to low $\mathrm{Sr}$ concentration coupled with a relatively high $\mathrm{P}$ content.
(2) The strontium content should exceed $200 \mathrm{ppm}$ in order to overcome the negative effect of P-alloy IX.

(3) Due to the Sr-P interaction, the standard deviation could be as high as $300 \%$ of the average values.

(4) In the absence of $\mathrm{P}$, that is, alloy 413S, the standard deviation is minimum coupled with high roundness (about 77\%).

3.1.2. Tensile Bars (Dendrite Arm Spacing $\sim 25 \mu \mathrm{m}$ ). Figure 6 displays the dependence of the morphology of eutectic 

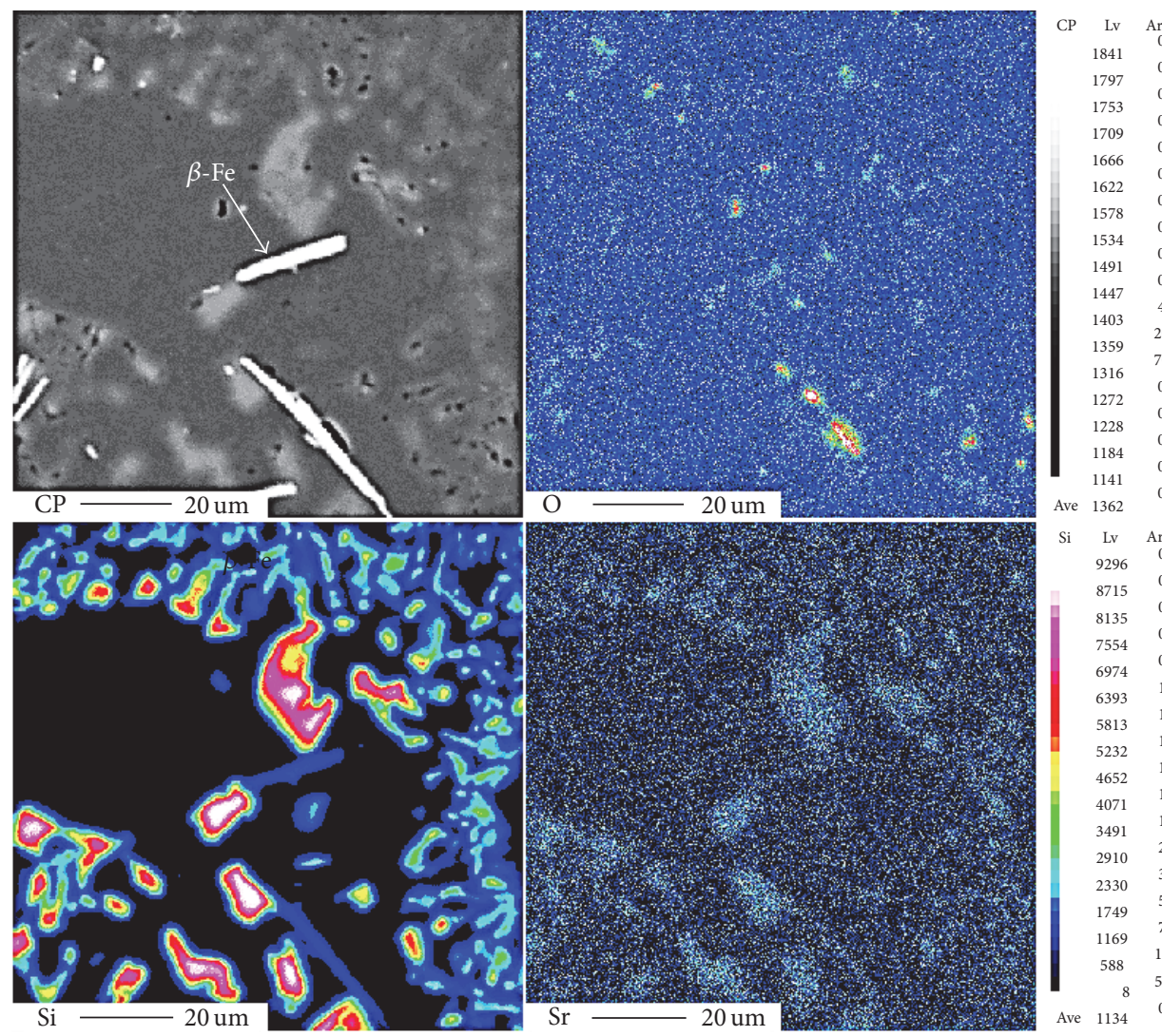

$\begin{array}{rcccc}\text { Lv } & \text { Area\% } & \text { Sr } & \text { Lv } & \text { Area\% } \\ 9296 & 0.0 & & 10 & 0.0 \\ 8715 & 0.2 & & 9 & 0.0 \\ 8135 & 0.5 & & 8 & 0.0 \\ 7554 & 0.7 & & 0.0 \\ 6974 & 0.9 & & 8 & 0.0 \\ 6393 & 1.0 & & 7 & 0.0 \\ 5813 & 1.0 & & 6 & 0.0 \\ 5232 & 1.1 & & 6 & 0.0 \\ 4652 & 1.2 & & 5 & 0.1 \\ 4071 & 1.3 & & 5 & 0.0 \\ 3491 & 1.8 & & 4 & 0.6 \\ 2910 & 2.5 & & 3 & 0.0 \\ 2330 & 3.7 & & 3 & 2.7 \\ 1749 & 5.2 & & 2 & 10.7 \\ 1169 & 7.4 & & 1 & 0.0 \\ 588 & 12.5 & & 1 & 32.4 \\ 8 & 58.8 & 0 & 53.5 \\ 1134 & 0.0 & \text { Ave } & 0 & 0.0\end{array}$

FIgURE 4: Distribution of Sr in the eutectic Si particles seen in the electron image in (a) of the A413 alloy sample shown in Figure 3(a).

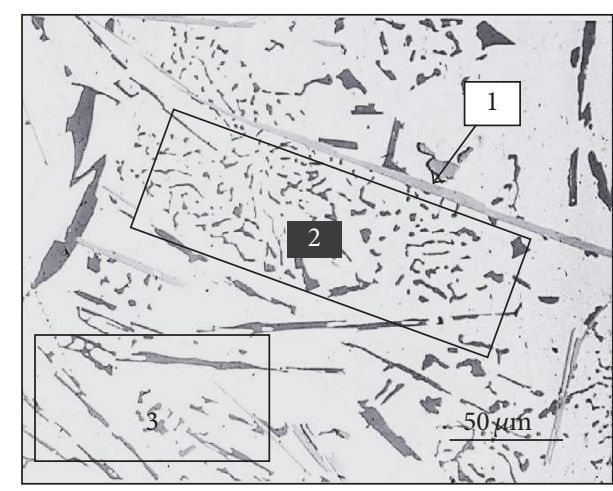

(a)

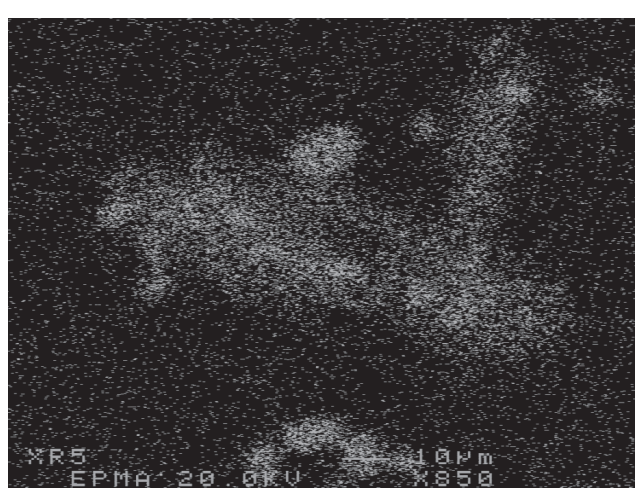

(b)

FIGURE 5: (a) Optical microstructure of alloy II (containing 103 ppm Sr and 53 ppm P): (1) $\beta$-Fe; (2) modified Si particles; (3) unmodified Si particles. (b) X-ray image of Sr distribution in a similar area to that marked (2) in (a).

Si particles on the alloy/heat-treated condition of samples sectioned from tensile bars. In the unmodified state, the $\mathrm{Si}$ particles precipitate in the form of long platelets with right angles (circled areas in Figures 6(a) and 6(b)). When Sr is added (about $240 \mathrm{ppm}$ ), the Si platelets transformed into fibrous or rod-like particles (thick arrow in Figure 6(c)). Samuel et al. [18] studied silicon twinning in hypoeutectic Al-Si alloys. The authors concluded that modification of eutectic Si by trace additions occurs due to a massive increase in the twin density caused by atomic effects at the growth interface. Twin densities in all modified samples are higher than those in unmodified alloys, and there are no significant differences between fine fibrous modification and refined plate-like modification.

Figures 6(d) and 6(e) display the fragmentation of the fibrous structure into polyhedral particles when the alloy was 


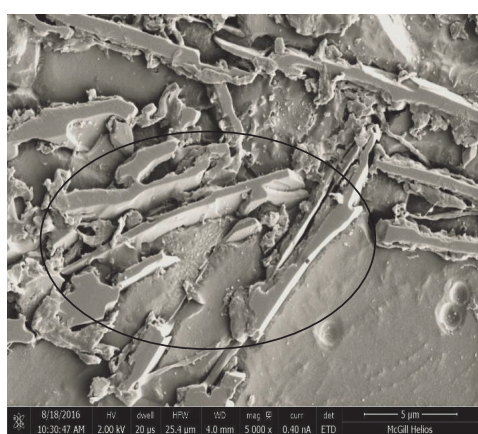

(a)

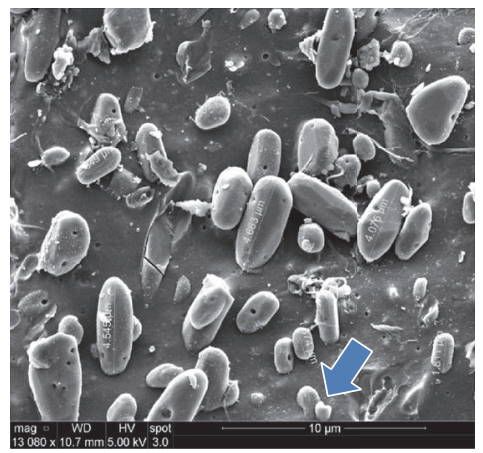

(d)

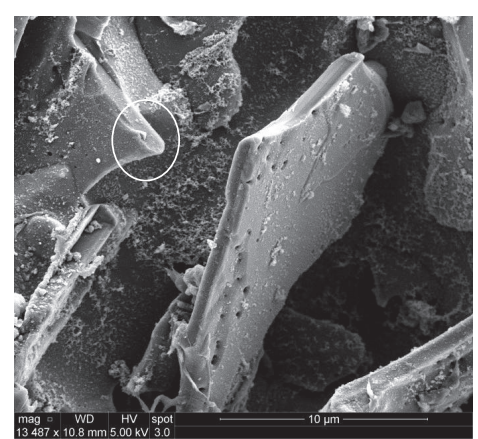

(b)

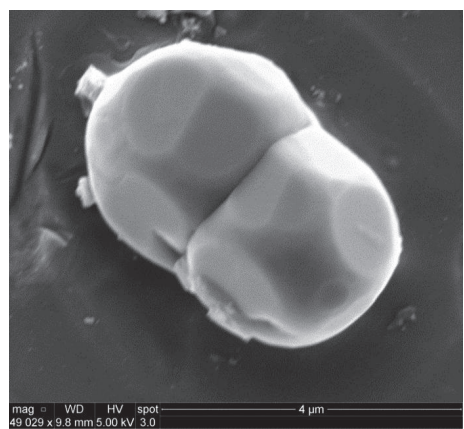

(e)

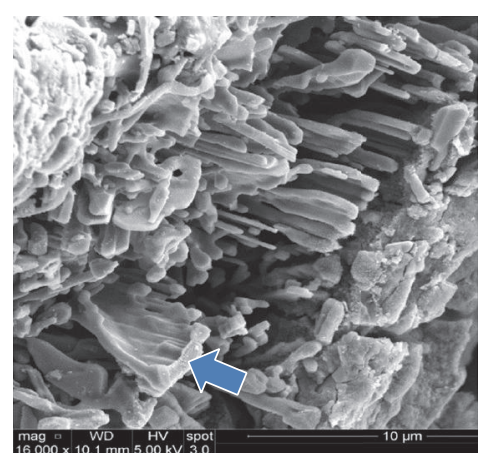

(c)

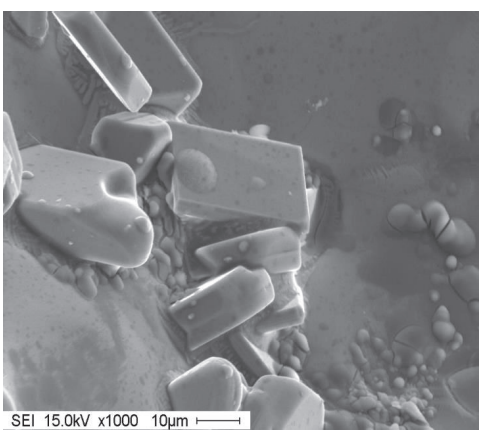

(f)

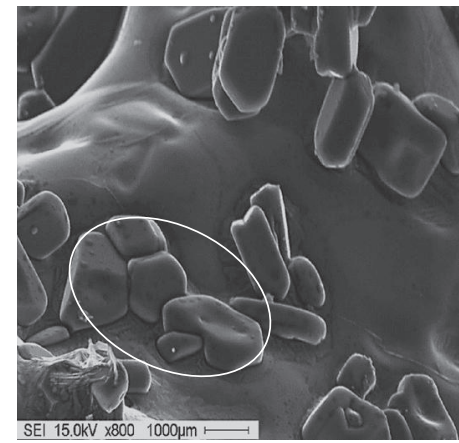

(g)

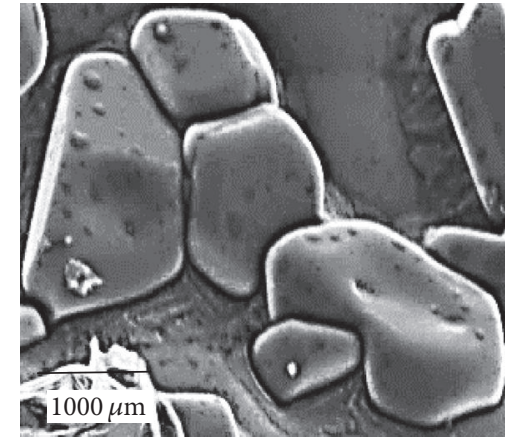

(h)

FIGURE 6: Variation in the morphology of eutectic Si particles in A413 alloy as a function of alloy/heat-treated condition: ((a) and (b)) as cast, unmodified, (c) as cast, modified with $240 \mathrm{ppm} \mathrm{Sr}$, ((d) and (e)) modified and SHT for $8 \mathrm{~h}$ at $505^{\circ} \mathrm{C}$, (f) modified and SHT for $8 \mathrm{~h}$ at $540^{\circ} \mathrm{C}$, and $(\mathrm{g})$ modified and SHT for $100 \mathrm{~h}$ at $540^{\circ} \mathrm{C}$. Note the polyhedral/polygonal morphology of the Si particles in (e-g); (h) an enlargement of the circled area in $(\mathrm{g})$ showing the growth of Si particles by coalescence of the adjacent Si particles. SHT: solution heat treated.

solutionized at $505^{\circ} \mathrm{C}$ for $8 \mathrm{~h}$. It is concluded that coarsening of the eutectic Si particles occurs either by the dissolution of the small particles, Oswald ripening technique [19] (thick arrow in Figure 6(d)), by the collision of the nearby particles (Figure 6(e)), or by both techniques simultaneously, resulting in a large difference in the particle size (standard deviation; see Table 4). Excessive heat treatment, that is, $8 \mathrm{~h}$ at $540^{\circ} \mathrm{C}$, would lead to incipient melting and remarkable increase in the size of the Si particles (Figures 6(f)-6(h)).

3.2. Tensile Properties: T6 Condition. Moustafa et al. [11, 20] performed a detailed study on the effect of alloying elements on the performance of 413 alloys. Their results showed that, with an increase in the solution treatment time, the Si particle characteristics (area, length, aspect ratio, roundness ratio, and density) in the base A413.1 and Mg-containing alloys become approximately the same. Both the $\mathrm{Mg}_{2} \mathrm{Si}$ and $\mathrm{Al}_{2} \mathrm{Cu}$ phases in $\mathrm{Al}-\mathrm{Si}$ alloys dissolve almost completely after solution treatment at $500^{\circ} \mathrm{C}$ for $8 \mathrm{~h}$ or less.

From the point of view of mechanical properties [19, 21], the hardness and strength (YS and UTS) of Mg-containing alloys decrease with the addition of $\mathrm{Sr}$ due to the sluggish dissolution of the $\mathrm{Al}_{5} \mathrm{Cu}_{2} \mathrm{Mg}_{8} \mathrm{Si}_{6}$ phase during solution treatment and a delay in the precipitation of $\mathrm{Mg}_{2} \mathrm{Si}$ or $\mathrm{Al}_{2} \mathrm{MgCu}$ 
TABLE 4: Characteristics of the eutectic Si particles.

\begin{tabular}{|c|c|c|c|c|c|}
\hline Alloy code & $\begin{array}{c}\text { Particle area } \\
\qquad \mu \mathrm{m}^{2}\end{array}$ & $\begin{array}{c}\text { Particle length } \\
\mu \mathrm{m}\end{array}$ & $\begin{array}{c}\text { Roundness } \\
\%\end{array}$ & Aspect ratio & $\begin{array}{c}\text { Density } \\
\text { particles } / \mathrm{mm}^{2}\end{array}$ \\
\hline \multirow{2}{*}{ A 413.0} & $\mu^{*}=37.27$ & $\mu=12.69$ & $\mu=57.19$ & $\mu=2.877$ & \multirow{2}{*}{2522} \\
\hline & $\sigma^{* *}=60.72$ & $\sigma=14.57$ & $\sigma=31.28$ & $\sigma=1.685$ & \\
\hline \multirow{2}{*}{$413 \mathrm{~S}$} & $\mu=0.92$ & $\mu=1.32$ & $\mu=77.7$ & $\mu=1.623$ & \multirow{2}{*}{130000} \\
\hline & $\sigma=7.17$ & $\sigma=1.12$ & $\sigma=13.2$ & $\sigma=0.556$ & \\
\hline \multirow[t]{2}{*}{$413 \mathrm{P}$} & $\mu=30.44$ & $\mu=10.64$ & $\mu=58.10$ & $\mu=2.692$ & \multirow[t]{2}{*}{3515} \\
\hline & $\sigma=58.99$ & $\sigma=14.89$ & $\sigma=33.43$ & $\sigma=1.662$ & \\
\hline \multirow[t]{2}{*}{ I } & $\mu=10.45$ & $\mu=7.229$ & $\mu=54.55$ & $\mu=3.273$ & \multirow{2}{*}{9063} \\
\hline & $\sigma=26.26$ & $\sigma=10.21$ & $\sigma=31.42$ & $\sigma=1.919$ & \\
\hline \multirow[t]{2}{*}{ II } & $\mu=14.59$ & $\mu=9.098$ & $\mu=64.16$ & $\mu=2.78$ & \multirow{2}{*}{17396} \\
\hline & $\sigma=17.70$ & $\sigma=5.299$ & $\sigma=24.27$ & $\sigma=0.9795$ & \\
\hline \multirow{2}{*}{ III } & $\mu=20.77$ & $\mu=8.977$ & $\mu=58.04$ & $\mu=2.797$ & \multirow{2}{*}{5390} \\
\hline & $\sigma=43.02$ & $\sigma=13.05$ & $\sigma=32.96$ & $\sigma=1.705$ & \\
\hline \multirow[t]{2}{*}{ IV } & $\mu=0.87$ & $\mu=1.46$ & $\mu=75.2$ & $\mu=1.903$ & \multirow{2}{*}{144000} \\
\hline & $\sigma=7.19$ & $\sigma=1.27$ & $\sigma=22.3$ & $\sigma=0.776$ & \\
\hline \multirow[t]{2}{*}{$\mathrm{V}$} & $\mu=0.76$ & $\mu=1.46$ & $\mu=78.30$ & $\mu=1.868$ & \multirow{2}{*}{143500} \\
\hline & $\sigma=7.28$ & $\sigma=1.27$ & $\sigma=20.61$ & $\sigma=0.762$ & \\
\hline \multirow[t]{2}{*}{ VI } & $\mu=0.73$ & $\mu=1.28$ & $\mu=78.6$ & $\mu=1.892$ & \multirow{2}{*}{145900} \\
\hline & $\sigma=7.29$ & $\sigma=1.06$ & $\sigma=20.3$ & $\sigma=0.804$ & \\
\hline \multirow[t]{2}{*}{ VII } & $\mu=0.80$ & $\mu=1.33$ & $\mu=78.6$ & $\mu=1.907$ & \multirow{2}{*}{135100} \\
\hline & $\sigma=7.33$ & $\sigma=1.19$ & $\sigma=20.2$ & $\sigma=0.806$ & \\
\hline \multirow[t]{2}{*}{ VIII } & $\mu=0.77$ & $\mu=1.38$ & $\mu=76.2$ & $\mu=1.97$ & \multirow{2}{*}{148200} \\
\hline & $\sigma=7.26$ & $\sigma=1.17$ & $\sigma=21.4$ & $\sigma=0.848$ & \\
\hline \multirow{2}{*}{ IX } & $\mu=1.88$ & $\mu=2.47$ & $\mu=75.7$ & $\mu=1.98$ & \multirow[t]{2}{*}{125000} \\
\hline & $\sigma=6.17$ & $\sigma=1.29$ & $\sigma=21.9$ & $\sigma=0.856$ & \\
\hline
\end{tabular}

${ }^{*}$ Average value; ${ }^{* *}$ standard deviation.

phases during artificial aging thereafter. The properties of the $\mathrm{Cu}$-containing alloys, however, remain unaffected by the addition of Sr. With the exception of $\mathrm{Ni}$, all alloying elements used improve hardness and strength, particularly after heat treatment. In the case of $\mathrm{Ni}$, addition of up to $1.41 \% \mathrm{Ni}$ is observed to decrease the mechanical properties in the T6 condition.

Figure 7 reveals the tensile properties of the present alloys following aging treatment. From the data presented in Figure 7, the following observations may be made:

(1) The UTS of all alloys decreased continuously with the increase in the aging treatment due to coarsening of the precipitated particles $[20,22]$.

(2) Although the YS decreased with aging temperature, the curves showed maxima and minima which may be interpreted in terms of the sequence of precipitation and coarsening of the different age hardening phases in these alloys [23], as shown in Figure 8.

(3) The ductility (represented by percent elongation) displayed continuous decrease with aging temperature with maxima and minima for the II, II, V, and IV alloys. The 413P and III alloys, however, revealed no response to aging temperature. It should be noted here that these two alloys contain very low levels of Sr and P.

(4) Although II, III, and IV alloys have more or less same amounts of $\mathrm{P}$, the percent elongations obtained from the II (103 ppm Sr) and IV (233 ppm Sr) alloys are superior to that obtained from alloy III ( $56 \mathrm{ppm} \mathrm{Sr}$ ).

(5) In general, all alloys containing sufficient $\mathrm{P}$ revealed percent elongations in the range of $4-12 \%$, as compared to the base alloy $413 \mathrm{P}(4-6 \%)$. 


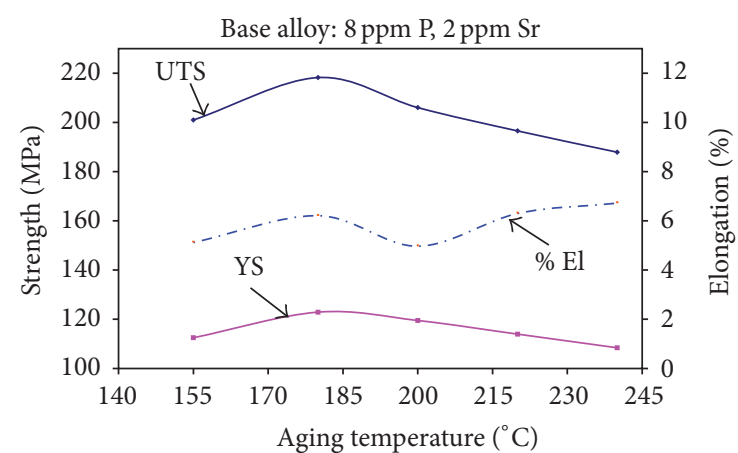

(a) $413 \mathrm{P}$

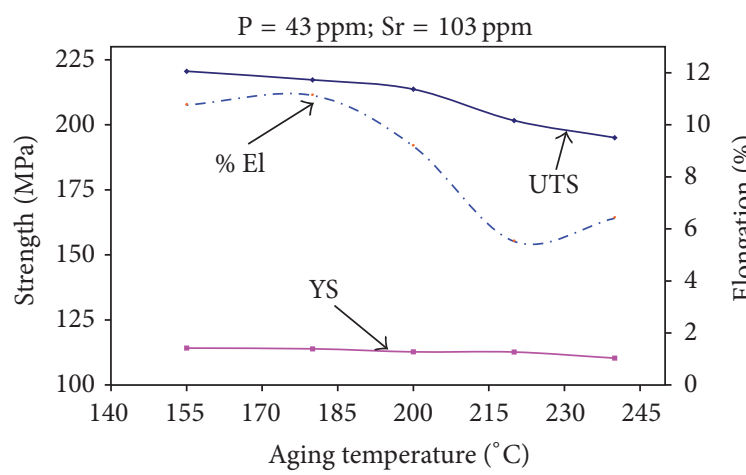

(c) II

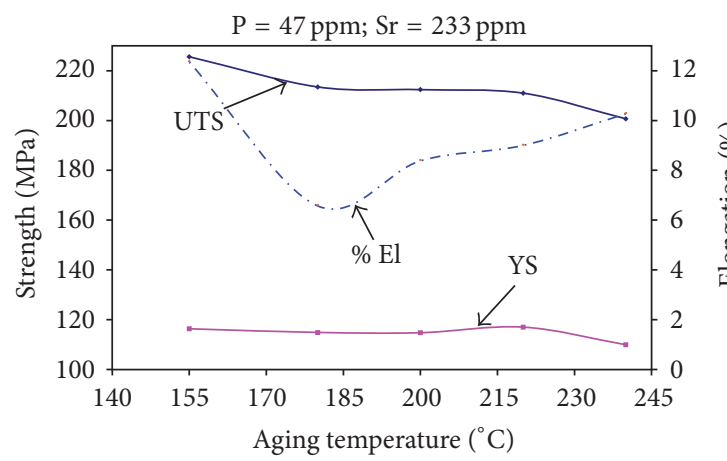

(e) IV

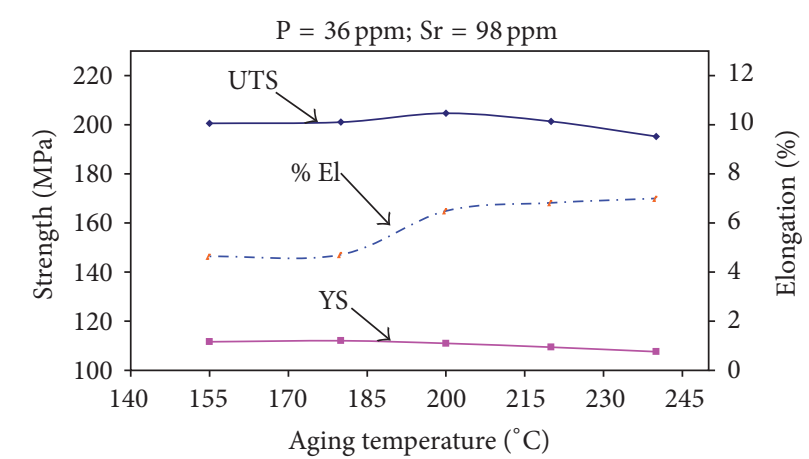

(b) I

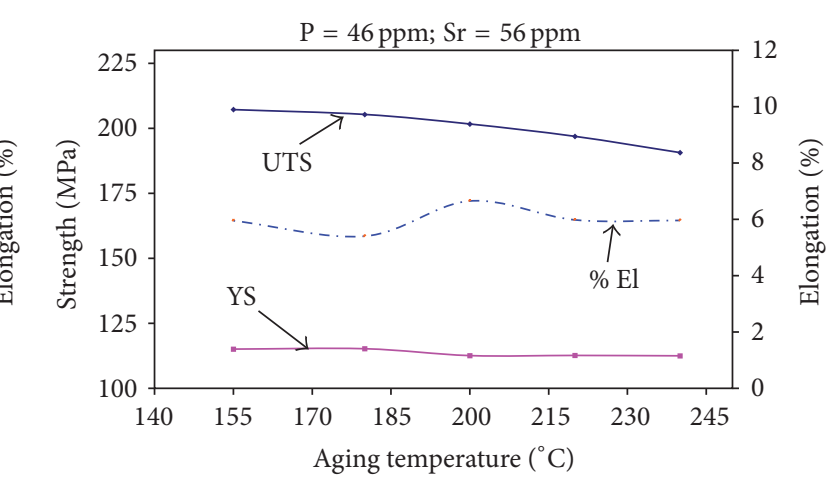

(d) III

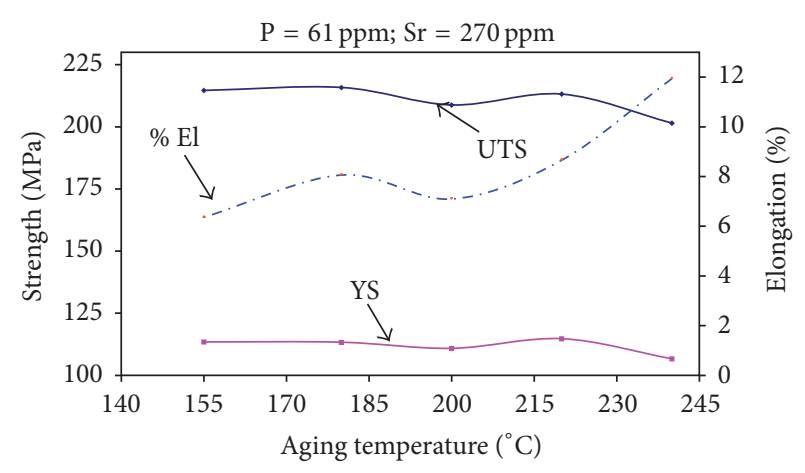

(f) $\mathrm{V}$

FIGURE 7: Variation in the tensile properties as a function of aging temperature for (a) base 413P alloy, (b) alloy I, (c) alloy II, (d) alloy III, (e) alloy IV, and (f) alloy V.

\section{Conclusions}

Based on the results obtained in the present study, the following conclusions may be drawn:

(1) The primary Si particles are nucleated on P-based compounds or oxide films.

(2) In the absence of $\mathrm{P}$, the coarsening of eutectic $\mathrm{Si}$ during solution heat treatment may occur by simultaneous dissolution of the fine particles (Oswald ripening mechanism) and collision of the nearby particles.

(3) At low $\mathrm{Sr}$ content (about $60 \mathrm{ppm}$ ), addition of P could lead to a demodified Si structure. Thus an increase in
Sr content beyond $200 \mathrm{ppm}$ is required to maintain full modification of the eutectic Si particles.

(4) Tensile properties of alloys containing more or less same amounts of $\mathrm{P}$ but with high $\mathrm{Sr}$ content $(103 \mathrm{ppm}$ and $233 \mathrm{ppm})$ are relatively higher than those obtained from alloy containing $56 \mathrm{ppm} \mathrm{Sr}$ due to Sr-P interaction.

(5) Well modified alloys with sufficient amount of Sr produce better mechanical properties compared to the base alloy when $\mathrm{P}$ is added in amounts of 50$60 \mathrm{ppm}$. 

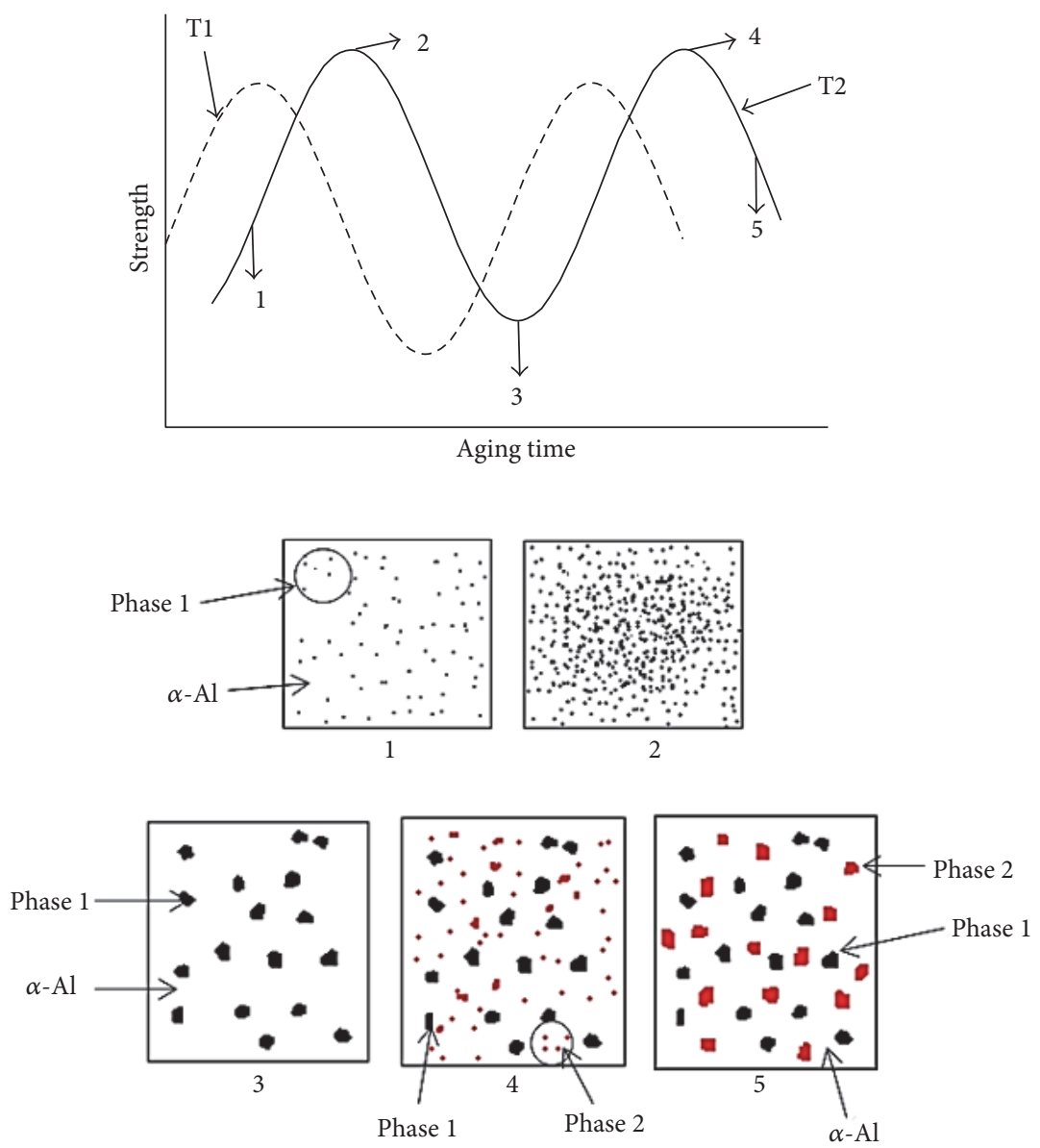

FIGURE 8: Schematic diagrams showing the possible precipitation, dissolution, and coarsening of the age hardening phases during the course of aging.

\section{Competing Interests}

The authors declare that they have no competing interests.

\section{Acknowledgments}

The authors would like to thank Ms. Amal Samuel for enhancing the quality of the images used in the present study.

\section{References}

[1] M. M. Haque and M. A. Maleque, "Effect of process variables on structure and properties of aluminium-Silicon piston alloy," Journal of Materials Processing Technology, vol. 300, no. 3-4, pp. 122-128, 1998.

[2] E. J. D. Martínez, M. A. Cisneros G, S. Valtierra, and J. Lacaze, "Effect of strontium and cooling rate upon eutectic temperatures of A319 aluminum alloy," Scripta Materialia, vol. 52, no. 6, pp. 439-443, 2005.

[3] J. H. Sokolowski, X.-C. Sun, G. Byczynski et al., “The removal of copper-phase segregation and the subsequent improvement in mechanical properties of cast 319 aluminium alloys by a twostage solution heat treatment," Journal of Materials Processing Technology, vol. 53, no. 1-2, pp. 385-392, 1995.
[4] F. Paray and J. E. Gruzleski, "Microstructure-mechanical property relationship in a 356 alloy. Part 1: microstructure," Cast Metals, vol. 7, pp. 29-40, 1994.

[5] H. Li, S. Shivkumar, S. Luo, and D. Apelian, "Influence of modification on the solution heat treatment response of cast AlSi-Mg alloys," Cast Metals, vol. 1, pp. 227-234, 1989.

[6] M. M. Makhlouf and H. V. Guthy, "The aluminum-silicon eutectic reaction: mechanisms and crystallography," Journal of Light Metals, vol. 1, no. 4, pp. 199-218, 2001.

[7] M. M. Makhlouf, S. Shankar, and Y. W. Riddle, "Mechanism of formation and chemical modification of the morphology of the eutectic phase in hypoeutectic aluminum silicon alloys," AFS Transactions 05-88, 2005.

[8] J. C. Weiss and C. R. Loper Jr., "Primary silicon in hypereutectic aluminum silicon casting alloys," AFS Transactions, vol. 32, pp. 51-62, 1987.

[9] M. A. Moustafa, C. Lepage, F. H. Samuel, and H. W. Doty, "Metallographic observations on phase precipitation in strontiummodified Al-11.7\% Si alloys: role of alloying elements," International Journal of Cast Metals Research, vol. 15, no. 6, pp. 609-626, 2003.

[10] Z. Li, A. M. Samuel, F. H. Samuel, C. Ravindran, S. Valtierra, and H. W. Doty, "Parameters controlling the performance of AA319-type alloys Part I. Tensile properties," Materials Science and Engineering A, vol. 367, no. 1-2, pp. 96-110, 2004. 
[11] M. A. Moustafa, F. H. Samuel, and H. W. Doty, "Effect of solution heat treatment and additives on the microstructure of Al-Si (A413.1) automotive alloys," Journal of Materials Science, vol. 38, no. 22, pp. 4507-4522, 2003.

[12] F. J. Tavitas-Medrano, J. E. Gruzleski, F. H. Samuel, S. Valtierra, and H. W. Doty, "Effect of Mg and Sr-modification on the mechanical properties of 319-type aluminum cast alloys subjected to artificial aging," Materials Science and Engineering A, vol. 480, no. 1-2, pp. 356-364, 2008.

[13] K. Al-Helal, I. C. Stone, and Z. Fan, "Simultaneous primary $\mathrm{Si}$ refinement and eutectic modification in hypereutectic Al-Si alloys," Transactions of the Indian Institute of Metals, vol. 65, no. 6, pp. 663-667, 2012.

[14] E. Samuel, A. M. Samuel, H. W. Doty, S. Valtierra, and F. H. Samuel, "Intermetallic phases in Al-Si based cast alloys: new perspective," International Journal of Cast Metals Research, vol. 27, no. 2, pp. 107-114, 2014.

[15] S.-M. Liang and R. Schmid-Fetzer, "Phosphorus in Al-Si cast alloys: thermodynamic prediction of the AlP and eutectic (Si) solidification sequence validated by microstructure and nucleation undercooling data," Acta Materialia, vol. 72, pp. 4156, 2014.

[16] J. Campbell, "Discussion of "Effect of strontium and phosphorus on eutectic Al-Si nucleation and formation of $\beta$-Al5FeSi in hypoeutectic Al-Si foundry alloys"," Metallurgical and Materials Transactions A, vol. 40, no. 5, pp. 1009-1010, 2009.

[17] J. Campbell and M. Tiryakioğlu, "Review of effect of P and Sr on modification and porosity development in Al-Si alloys," Materials Science and Technology, vol. 26, no. 3, pp. 262-268, 2010.

[18] A. M. Samuel, H. W. Doty, S. Valtierra, and F. H. Samuel, "Effect of grain refining and Sr-modification interactions on the impact toughness of Al-Si-Mg cast alloys," Materials \& Design, vol. 56, pp. 264-273, 2014.

[19] M. F. Ibrahim, E. M. Elgallad, S. Valtierra, H. W. Doty, and F. H. Samuel, "Metallurgical parameters controlling the eutectic silicon charateristics in Be-treated Al-Si-Mg alloys," Materials, vol. 9, no. 2, article 78, 17 pages, 2016.

[20] M. A. Moustafa, F. H. Samuel, and H. W. Doty, "Effect of solution heat treatment and additives on the hardness, tensile properties and fracture behaviour of Al-Si (A413.1) automotive alloys," Journal of Materials Science, vol. 38, no. 22, pp. 45234534, 2003.

[21] K. Nogita, J. Drennan, and A. K. Dahle, "Evaluation of silicon twinning in hypo-eutectic Al-Si alloys," Materials Transactions, vol. 44, no. 4, pp. 625-628, 2003.

[22] N. R. Andrade, J. E. Gruzleski, F. H. Samuel, S. Valtierra, and H. W. Doty, "Age-hardening precipitates in cast 319 aluminum alloys," in Proceedings of the 45th Annual Conference of Metallurgists of CIM, International Symposium on Aluminium: From Raw Materials to Applications, pp. 104-114, Montreal, Canada, 2006.

[23] M. A. Moustafa, A. M. Samuel, F. H. Samuel, and H. W. Doty, "Precipitation of intermetallic phases in Sr-modified eutectic Al-Si alloys," in Proceedings of the 7th Arab Foundry Symposium (ARABCAST '08), Sharm El-Sheikh, Egypt, 2008. 

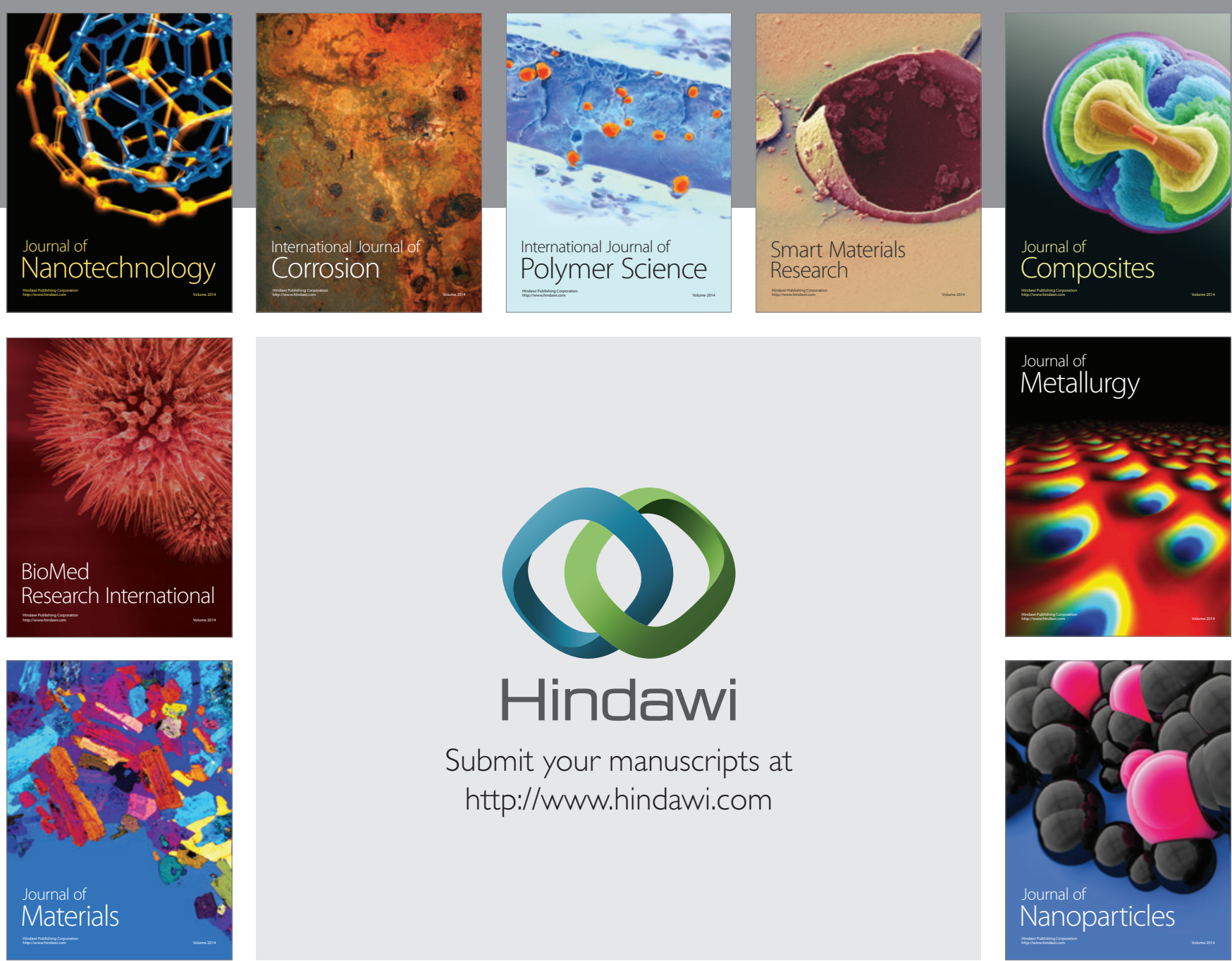

\section{Hindawi}

Submit your manuscripts at

http://www.hindawi.com

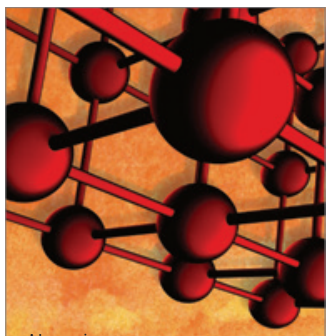

Materials Science and Engineering
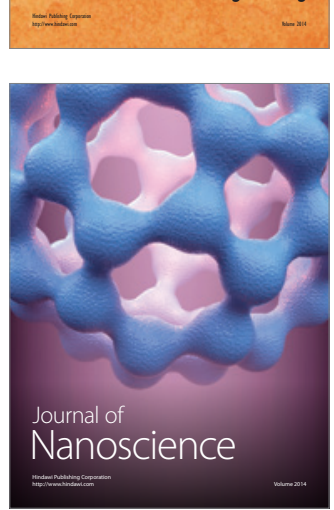
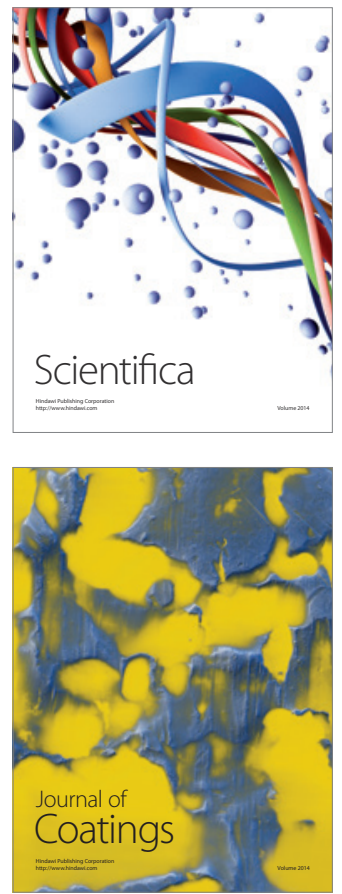
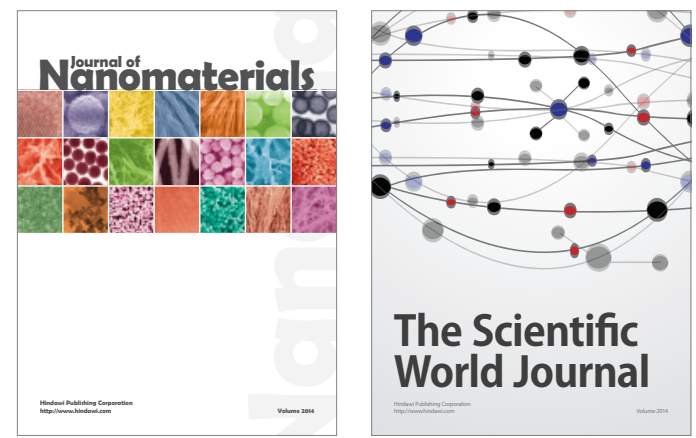

The Scientific World Journal
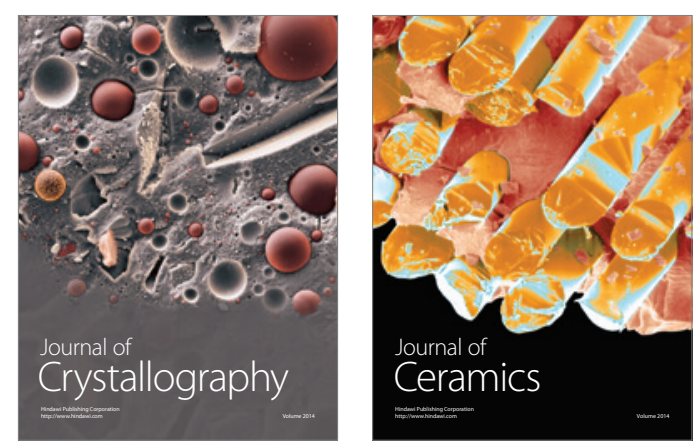
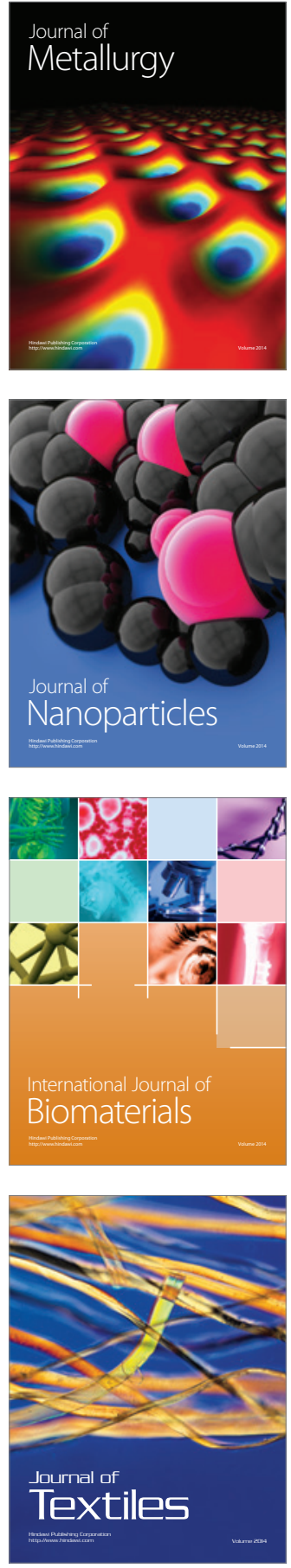